Justin R. Howell

\title{
The Pharisees and Figured Speech in Luke-Acts
}

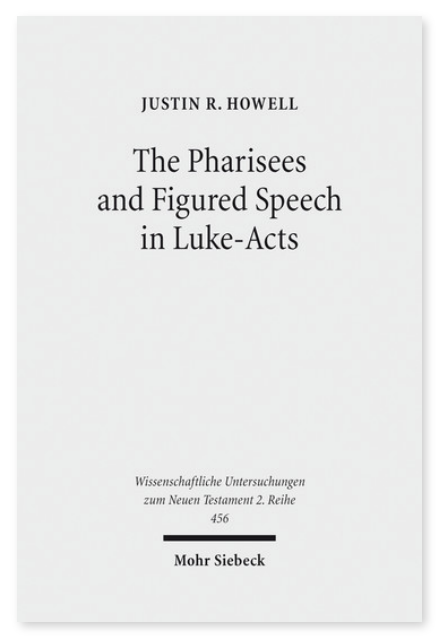

2017. XII, 386 Seiten. WUNT II 456

ISBN 978-3-16-155024-9

DOI 10.1628/978-3-16-155024-9

eBook PDF 109,00€

ISBN 978-3-16-155023-2

fadengeheftete Broschur 109,00€
[Die Pharisäer und die figurierte Rede im lukanischen Doppelwerk.]

Veröffentlicht auf Englisch.

Es herrscht wissenschaftlicher Konsens darüber, dass Lukas den Pharisäern ambivalent gegenüberstand oder zumindest, dass er seinen Lesern eine mehrdeutiges Bild von ihnen lieferte. Frühere Beurteilungen der lukanischen Pharisäer beantworteten jedoch nicht die Frage, warum Lukas einen solchen Eindruck dieser Charaktere vermittelt und außerdem, was sich hinter dem rhetorischen Effekt der Mehrdeutigkeit verbirgt. Justin R. Howell bewertet die langjährige Debatte über die Pharisäer im lukanischen Doppelwerk neu. Er vertritt die These, dass es diese Mehrdeutigkeit gibt, weil der Autor in seinen Darstellungen ein Stilmittel anwendet, welches die antiken, griechisch-römischen Rhetoriker als »figurierte Rede« bezeichnen. Die Tatsache, dass die lukanischen Pharisäer einigen Lesern als zweideutig erscheinen, heißt nicht unbedingt, dass Lukas innen gegenüber ebenfalls unentschieden oder ambivalent war, da die Anwendung von figurierter Rede eine klare und kritische Haltung gegenüber den betreffenden Personen voraussetzt.

Justin R. Howell Born 1978; 2016 PhD in New Testament and Early Christian Literature from the University of Chicago Divinity School.
Jetzt bestellen:

https://mohrsiebeck.com/buch/the-pharisees-and-figured-speech-in-luke-acts-9783161550249?no_cache=1 order@mohrsiebeck.com

Telefon: +49 (0)7071-923-17

Telefax: +49 (0)7071-51104 